\title{
Borderline personality disorder
}

\section{Joel Paris}

\section{Abstract}

BORDERLINE PERSONALITY DISORDER is a chronic psychiatric disorder characterized by marked impulsivity, instability of mood and interpersonal relationships, and suicidal behaviour that can complicate medical care. Identifying this diagnosis is important for treatment planning. Although the cause of borderline personality disorder is uncertain, most patients improve with time. There is an evidence base for treatment using both psychotherapy and psychopharmacology. The clinical challenge centres on managing chronic suicidality.

\section{CMAJ 2005;172(12):1579-83}

Case

Colleen, a 22-year old student, is seen for a psychiatric assessment after presenting to the emergency department because of taking an overdose of acetaminophen pills. Although the immediate precipitant to her suicide attempt was a break-up with her boyfriend, she has a history of multiple suicide attempts since the age of 14 . Colleen reports that she has daily mood swings, from depression to intense anger, and that she often cuts herself on the wrists and arms to relieve dysphoria. When stressed, she experiences feelings of unreality, sometimes hearing a voice telling her to kill herself. Colleen has had highly problematic relationships with men, falling quickly in and out of love and feeling that her life depends on them, even when they have behaved abusively toward her. What is the appropriate diagnosis and management of this patient?

$\mathrm{P}$ ersonality disorders constitute a major group in the classification of mental disorders. According to the Diagnostic and Statistical Manual of Mental Disorders, fourth edition, text revision (DSM-IV-TR), ${ }^{1}$ these conditions are defined by maladaptive personality characteristics beginning early in life that have consistent and serious effects on functioning. Borderline personality disorder (BPD) is frequently seen in clinical practice. ${ }^{2}$ Characterized by emotional turmoil and chronic suicidality (suicide ideation and attempts), this type of personality disorder presents some of the most difficult and troubling problems in all of $\vec{\infty}$ psychiatry.

\section{Epidemiology}

Epidemiologic studies of personality disorders are at an early stage of development. Community surveys of adults have indicated that the prevalence of BPD is close to $1 \%$ (similar to that of schizophrenia), ${ }^{3,4}$ About $80 \%$ of patients receiving therapy for BPD are women, ${ }^{2}$ but sex differences are less striking in community samples. ${ }^{4}$ As is the case for personality disorders in general, BPD is associated with lower social class and lower levels of education. ${ }^{3,4}$

\section{Causes: biological, psychological and social}

We are only beginning to understand the causes of BPD. As with most mental disorders, no single factor explains its development, and multiple factors (biological, psychological and social) all play a role.

The biological factors in personality disorders consist of temperamental (inborn or heritable) characteristics that present in adulthood as stable personality traits: patterns of thought, affect and behaviour that characterize individuals and are stable over time. ${ }^{5}$ Heritable factors account for about half of the variability in virtually all traits that have been studied. ${ }^{6}$ Specifically, both affective instability ${ }^{6}$ and impulsivity $^{7}$ have a heritable component of this magnitude, and studies involving twins have demonstrated that BPD itself shows a similar genetic influence. ${ }^{8}$ Also, family history studies have found that impulsive disorders such as antisocial personality and substance abuse are particularly common among firstdegree relatives of patients with BPD. ${ }^{9}$ Studies of central neurotransmitter activity have shown that impulsive traits, a major component of $\mathrm{BPD}$, are associated with deficits in central serotonergic functioning. ${ }^{10,11}$ However, the biological correlates of affective instability are unknown, and no markers specific to the overall disorder have been identified..$^{10}$

The psychological factors in BPD can be striking but are not consistent. BPD first presents clinically in adolescence, at a mean age of 18 years. ${ }^{12}$ Although many patients describe adversities such as family dysfunction as well as mood and impulsive symptoms that go back to childhood, longitudinal data are needed to determine the precise influence of early risk factors. ${ }^{13}$ Reports of a high frequency of traumatic events during childhood in this population need to take into account community studies, which show extensive resilience following trauma, particularly for less severe adversities. ${ }^{13}$ The most careful studies have shown that a quarter of patients with BPD describe sexual abuse from a caretaker ${ }^{14}$ and that about a third report severe forms of abuse. ${ }^{15}$ However, although child abuse is clearly a risk factor, it is not specific to BPD. ${ }^{13}$ In general, adverse life events are not consistently pathogenic by themselves but, rather, produce sequelae in vulnerable populations. ${ }^{16}$ 
Social factors in BPD are suggested by indirect evidence. Thus far, there have been no cross-cultural studies of BPD, although characteristic symptoms such as recurrent suicide attempts are less common in traditional societies, in which there is little change from one generation to the next, but are on the increase in modern societies and in societies undergoing rapid change. ${ }^{17}$

\section{Clinical presentation and diagnosis}

The term "borderline" is a misnomer, based on an old theory that this form of pathology lies on a border between psychosis and neurosis. Actually, BPD is a complex syndrome whose central features are instability of mood, impulse control and interpersonal relationships. ${ }^{2}$ Box 1 presents the DSM-IV-TR ${ }^{1}$ criteria, reorganized in relation to these basic dimensions, as well as cognitive symptoms. Since the DSM-IV-TR requires only 5 of 9 criteria to be present, making a diagnosis on this basis leads to heterogeneity; more precise research definitions have been developed that require high scores for all 3 dimensions. ${ }^{18}$

\section{Box 1: Diagnostic criteria of borderline personality} disorder*

Borderline personality disorder is defined as a pervasive pattern of instability of interpersonal relationships, self-image and affects, and marked impulsivity beginning by early adulthood and present in a variety of contexts, as indicated by 5 or more of the following symptoms:

Affective symptoms

- Affective instability due to a marked reactivity of mood (e.g., intense episodic dysphoria, irritability or anxiety usually lasting a few hours and only rarely more than a few days)

- Inappropriate, intense anger or difficulty controlling anger (e.g., frequent displays of temper, constant anger, recurrent physical fights)

- Chronic feelings of emptiness

Impulsive symptoms

- Recurrent suicidal behaviour, gestures or threats, or self-mutilating behaviour

- Impulsivity in at least 2 areas that are potentially self-damaging (e.g., spending, sex, substance abuse, reckless driving, binge eating)

- A pattern of unstable and intense interpersonal relationships characterized by alternating between extremes of idealization and devaluation

Interpersonal symptoms

- Frantic efforts to avoid real or imagined abandonment

- Identity disturbance: markedly and persistently unstable self-image or sense of self

Cognitive symptoms

- Transient, stress-related paranoid ideation or severe dissociative symptoms

*Based on DSM-IV-TR criteria' and reorganized in relation to basic trait dimensions
The affective symptoms in BPD involve rapid mood shifts, in which emotional states tend to last only a few hours. ${ }^{19}$ When affective instability is monitored with standardized instruments,$^{20}$ emotions are found to be intense but reactive to external circumstances, with a strong tendency toward angry outbursts. Levels of affective instability are most predictive of suicide attempts. ${ }^{21}$ Impulsive symptoms include a wide range of behaviours and are central to diagnosis. ${ }^{22}$ The combination of affective instability with impulsivity in $\mathrm{BPD}^{23}$ helps account for a clinical presentation marked by chronic suicidality and by instability of interpersonal relationships. ${ }^{23}$ Finally, cognitive symptoms are also frequent. In one case series, ${ }^{24}$ about $40 \%$ of 50 patients with BPD had quasi-psychotic thoughts. In another series, ${ }^{25} 27 \%$ of 92 patients experienced psychotic episodes. In a third series, ${ }^{26}$ psychotic symptoms were found to predict self-harm in patients with personality disorders.

$\mathrm{BPD}$ is common in practice. A recent study involving patients in an emergency department who had attempted suicide showed that $41 \%$ of those with a history of multiple suicide attempts met the criteria for BPD this disorder. ${ }^{27}$ However, many cases are also seen in primary care settings. Data from a survey conducted in a US urban primary care practice indicated that BPD was present in $6.4 \%$ of a sample of 218 patients. ${ }^{28}$

Because of the wide range of symptoms seen in BPD that are also typical of other disorders (Table 1), such as mood and anxiety disorders, substance abuse and eating disorders, ${ }^{29}$ patients may be felt to have one of these conditions while their BPD goes undetected. The most common disorder associated with BPD is depression, but in $\mathrm{BPD}$, symptoms are usually associated with mood instability rather than with the extended and continuous periods of lower mood seen in classic mood disorders. ${ }^{19}$ Also, because of characteristic mood swings, BPD is often mistaken for bipolar disorder..$^{30}$ However, patients with BPD do not show continuously elevated mood but instead exhibit a pattern of rapid shifts in affect related to environmental events, with "high" periods that last for hours rather than for days or weeks..$^{30} \mathrm{BPD}$ may be mistaken for schizophrenia; however, instead of long-term psychotic symptoms, patients with BPD experience "micropsychotic" phenomena of short duration (lasting hours or at most a few days), auditory hallucinations without loss of insight (patients with schizophrenia do not recognize that a hallucination is imaginary, whereas patients with BPD do), paranoid trends and depersonalization states in which patients experience themselves or their environment as unreal. ${ }^{24}$ Finally, patients with BPD are at increased risk of substance abuse, which forms part of the clinical picture of widespread impulsivity. ${ }^{2}$

To diagnose BPD in practice, clinicians must first establish whether a patient has the overall characteristics of a personality disorder described in the DSM-IV-TR; ${ }^{1}$ that is, long-term problems affecting cognition, mood, interpersonal functioning and impulse control that begin early in 
life and are associated with maladaptive personality traits, such as neuroticism (being easily prone to anxiety or depression, or both) or impulsivity. Personality disorders can often account better for the multiplicity and chronicity of symptoms than can alternative diagnoses such as mood or anxiety disorders.

The next step is a personality assessment, which requires a good history. Although practitioners will be able to obtain needed information from most patients during a routine visit, they may also, with the patient's consent, wish to speak to family members or friends.

The final step is to determine the category that best fits the clinical picture. To diagnose BPD, clinicians need to establish that patterns of affective instability, impulsivity and unstable relationships have been consistent over time.

\section{Natural course and prognosis}

Managing patients with BPD can be burdensome for clinicians because they may have to deal with repeated suicide threats and attempts over years. Also, patients with BPD do not easily respect boundaries and may become overly attached to their therapists. ${ }^{31}$ When practitioners fail to diagnose BPD, they may be at risk of becoming overinvolved with patients who suffer greatly but can be personally appealing to the physicians.

Fortunately, most patients with BPD improve with time. ${ }^{32-34}$ About $75 \%$ will regain close to normal functioning by the age of 35 to 40 years, and $90 \%$ will recover by the age of $50 .{ }^{32}$ Unfortunately, about 1 in 10 patients eventually succeeds in committing suicide. ${ }^{35}$ However, this outcome is difficult to predict, and $90 \%$ of patients improve despite having threatened to end their lives on multiple occasions. The mechanism of recovery in BPD is not fully understood, but impulsivity generally decreases with age, and patients learn over time how to avoid the situations that give them the most trouble (e.g., intense love affairs), finding stable niches that provide the structure they need. ${ }^{35}$

\section{Management}

BPD is a therapeutic challenge. A series of randomized controlled trials of pharmacotherapy and psychotherapy $^{36-47,50,52-54}$ have been published; however, the trials had a number of defects, most particularly small samples, attrition and durations that were too short (usually 8-12 weeks) for a chronic disorder that can last for years (a summary of the trial results is available in an online table at www.cmaj .ca/cgi/content/full/172/12/1579/DC1). Finally, outcomes in these studies were generally measured by self-report and did not indicate whether the clinical picture had actually shown full remission.

The pharmacologic treatment of BPD remains limited in scope. By and large, the result can be described as a mild degree of symptom relief. A number of agents, including low-dose atypical neuroleptics, ${ }^{38}$ specific serotonin reuptake inhibitors ${ }^{39,41-43}$ and mood stabilizers, ${ }^{44,45}$ all alleviate impulsive symptoms. However, antidepressants are much less effective for mood symptoms in BPD patients than in patients without a personality disorder. ${ }^{48}$ Benzodiazepines are not very useful in BPD and carry some danger of abuse..$^{9}$

Thus, although several drugs "take the edge off" symptoms, they do not produce remission of BPD. Failure to understand this point has led to polypharmacy regimens, on the assumption that multiple drugs are needed to target all aspects of the disorder. The result is that many patients receive 4-5 agents - with all their attendant side effects ${ }^{12}-$ in the absence of evidence from clinical trials supporting the efficacy of such combinations. Future research may lead to the development of agents more specific to the symptoms seen in BPD.

The mainstay of treatment for BPD is still psychotherapy. Dialectical behaviour therapy is a form of cognitive behavioural therapy that targets affective instability and impulsivity, using group and individual sessions to teach patients how to regulate their emotions. This form of behav-

\begin{tabular}{|c|c|c|}
\hline Symptom & BPD & Other diagnosis \\
\hline Depression & $\begin{array}{l}\text { Lowered mood that is either } \\
\text { short-lived or subclinical and } \\
\text { intermittent }\end{array}$ & $\begin{array}{l}\text { Major depressive episode: Lowered } \\
\text { mood that is extended and continuous }\end{array}$ \\
\hline Mood swings & $\begin{array}{l}\text { Rapid shifts in mood from depression } \\
\text { to anger, often lasting only hours or } \\
\text { days and precipitated by } \\
\text { environmental events }\end{array}$ & $\begin{array}{l}\text { Bipolar disorder: Shifts in mood from } \\
\text { depression to mania, lasting weeks to } \\
\text { months and usually having no } \\
\text { precipitating event }\end{array}$ \\
\hline Cognitive dysfunction & $\begin{array}{l}\text { Auditory hallucinations that are } \\
\text { intermittent and related to stress and } \\
\text { are recognized as hallucinations by } \\
\text { the patient }\end{array}$ & $\begin{array}{l}\text { Schizophrenia: Hallucinations, mainly } \\
\text { auditory, that are often continuous and } \\
\text { are not recognized as hallucinations by } \\
\text { the patient }\end{array}$ \\
\hline Paranoid ideation & Nondelusional trends & Schizophrenia: Fixed delusions \\
\hline Depersonalization & $\begin{array}{l}\text { Feelings of unreality that are related } \\
\text { to stress }\end{array}$ & Schizophrenia: Infrequent \\
\hline
\end{tabular}


iour therapy has been shown to be effective in bringing suicidal behaviours under control within a year. ${ }^{50-53}$ However, whether this method is effective in the long term is unknown. There is evidence from a randomized controlled trial supporting the use of a modified form of psychoanalytic therapy in a day-treatment setting that also makes us of cognitive techniques..$^{54}$

Unfortunately, these forms of psychotherapy for BPD are expensive in terms of resources and are not generally available. In practice, therapy tends to be practical and supportive. Practitioners who manage these cases can also use educational materials for patients and their families. ${ }^{31}$

\section{Managing suicidality}

The main problem that practitioners face in managing cases of BPD is chronic suicidality. Physicians in primary care settings are prepared to care for many patients with psychotic disorders but are likely to ask psychiatrists to manage patients who make repeated suicide threats and attempts, or to suggest hospital admission. However, there has been little research on the effectiveness of hospitalization for the treatment of BPD and no evidence that it prevents completion of suicide. ${ }^{55}$

Suicidality in BPD peaks when patients are in their early 20 s, but completed suicide is most common after $30^{35}$ and usually occurs in patients who fail to recover after many attempts at treatment. In contrast, suicidal actions such as impulsive overdoses, most often seen in younger patients, do not usually carry a high short-term risk and function to communicate distress. ${ }^{56}$ Self-mutilating behaviours such as chronic cutting, often referred to as "suicidal," are problematic but are not associated with suicidal intent and instead serve to regulate dysphoric emotional states. ${ }^{56}$ Practitioners should move beyond their concerns about these patients and instead concentrate on managing symptoms and the life problems that exacerbate suicidal thoughts or behaviours.

\section{Conclusions}

The majority of patients with BPD are seen in psychiatric clinics or in primary care. The keys to successful management include making an accurate diagnosis, maintaining a supportive relationship with the patient and establishing limited goals. Although BPD may persist for years, it does not last forever, and one can be reasonably optimistic that most patients will recover with time. Psychotherapy can help speed up this process. The most effective forms of treatment have been developed by psychologists, and therefore when making a referral, physicians should consider a patient's ability to pay for such therapy.

More research into the causes of BPD is needed, the results of which may help to develop evidence-based approaches to treatment that are practical and specifically designed for this challenging disorder.

\section{The case revisited}

Colleen's symptoms clearly meet the diagnostic criteria for BPD (mood swings, impulsivity, suicidality, unstable relationships and micropsychotic phenomena), a clinical picture that could not readily be accounted for by a diagnosis of depression alone. Her family physician talks to her about the disorder and refers her to a psychiatrist to confirm the diagnosis. Colleen is seen for weekly psychotherapy sessions over the next 6 months by a psychologist at her university student health service, who applies established principles of management for this condition. ${ }^{31}$ In addition, her family physician prescribes a selective serotonin reuptake inhibitor to help control her impulsivity to a point where she stops cutting herself.

This article has been peer reviewed.

From the Department of Psychiatry, McGill University, and the Sir Mortimer B. Davis-Jewish General Hospital, Montréal, Que.

Competing interests: None declared.

\section{References}

1. Diagnostic and statistical manual of mental disorders. 4th ed, text revision. Washington: American Psychiatric Association; 2000.

2. Skodol AE, Gunderson JG, Pfohl B, Widiger TA, Livesley WJ, Siever LJ. The borderline diagnosis. I: Psychopathology, comorbidity, and personality structure. Biol Psychiatry 2002;51:936-50.

3. Samuels J, Eaton WW, Bienvenu J, Clayton P, Brown H, Costa PT, et al. Prevalence and correlates of personality disorders in a community sample. $\mathrm{Br}$ 7 Psychiatry 2002;180:536-42.

4. Torgersen S, Kringlen E, Cramer V. The prevalence of personality disorders in a community sample. Arch Gen Psychiatry 2001;58:590-6.

5. Rutter M. Temperament, personality, and personality development. Br 7 Psychiatry 1987;150:443-8.

6. Livesley WJ, Jang KL, Vernon PA. Phenotypic and genetic structure of traits delineating personality disorder. Arch Gen Psychiatry 1998;55:941-94.

7. Hinshaw SP. Impulsivity, emotion regulation, and developmental psychopathology: specificity versus generality of linkages. Ann N Y Acad Sci 2003;1008:149-59.

8. Torgersen S, Lygren S, Oien PA, Skre I, Onstad S, Edvardsen J, et al. A twin study of personality disorders. Compr Psychiatry 2000;41:416-25.

9. White CN, Gunderson JG, Zanarini MC, Hudson JI. Family studies of borderline personality disorder: a review. Harv Rev Psychiatry 2003;11:8-19.

10. Gurvits IG, Koenigsberg HW, Siever LJ. Neurotransmitter dysfunction in patients with borderline personality disorder. Psychiatr Clin North Am 2000; 23:27-40.

11. Paris J, Zweig-Frank H, Ng F, Schwartz G, Steiger H, Nair V. Neurobiological correlates of diagnosis and underlying traits in patients with borderline personality disorder compared with normal controls. Psychiatry Res 2004;121:239-52.

12. Zanarini MC, Frankenburg FR, Khera GS, Bleichmar J. Treatment histories of borderline inpatients. Compr Psychiatry 2001;42:144-50.

13. Paris J. Childhood trauma as an etiological factor in the personality disorders. 7 Personal Disord 1997;11:34-49.

14. Zanarini MC. Childhood experiences associated with the development of borderline personality disorder. Psychiatr Clin North Am 2000;23:89-101.

15. Paris J, Zweig-Frank H, Guzder J. Psychological risk factors for borderline personality disorder in female patients. Compr Psychiatry 1994:35:301-5.

16. Monroe SM, Simons AD. Diathesis-stress theories in the context of life stress research. Psychol Bull 1991;110:406-25.

17. Paris J. Social factors in the personality disorders. New York: Cambridge University Press; 1996.

18. Zanarini MC, Gunderson JG, Frankenburg FR. The revised diagnostic interview for borderlines: discriminating BPD from other axis II disorders. 7 Personal Disord 1989;3:10-8.

19. Gunderson JG, Phillips KA. A current view of the interface between borderline personality disorder and depression. Am f Psychiatry 1991;148:967-75.

20. Henry C, Mitropoulou V, New AS, Koenigsberg HW, Silverman J, Siever LJ. Affective instability and impulsivity in borderline personality and bipolar II disorders: similarities and differences. 7 Psychiatr Res 2001;35:307-12. 
21. Yen S, Shea MT, Sanislow CA, Grilo CM, Skodol AE, Gunderson JG, et al. Borderline personality disorder criteria associated with prospectively observed suicidal behavior. Am 7 Psychiatry 2004;161:1296-8.

22. Links PS, Steiner M, Offord DR, Eppel A. Characteristics of borderline personality disorder: a Canadian study. Can 7 Psychiatry 1988;33:336-40.

23. Siever LJ, Torgersen S, Gunderson JG, Livesley WJ, Kendler KS. The borderline diagnosis. III: Identifying endophenotypes for genetic studies. Biol Psychiatry 2002;51:964-8.

24. Zanarini MC, Gunderson JG, Frankenburg FR. Cognitive features of borderline personality disorder. Am 7 Psychiatry 1990;147:57-63.

25. Miller FT, Abrams T, Dulit R, Fyer M. Psychotic symptoms in patients with borderline personality disorder and concurrent axis I disorder. Hosp Community Psychiatry 1993;44:59-61.

26. Dowson JH, Sussams P, Grounds AT, Taylor J. Associations of self-reported past "psychotic" phenomena with features of personality disorders. Compr Psychiatry 2000;41:42-8.

27. Forman EM, Berk MS, Henriques GR, Brown GK, Beck AT. History of multiple suicide attempts as a behavioral marker of severe psychopathology. Am 7 Psychiatry 2004;161:437-43.

28. Gross R, Olfson M, Gameroff M, Shea S, Feder A, Fuentes M, et al. Borderline personality disorder in primary care. Arch Intern Med 2002;162:53-60.

29. Zanarini NC, Frankenburg FR, Dubo ED, Sickel AE, Trikha A, Levin A, et al. Axis I comorbidity of borderline personality disorder. Am 7 Psychiatry 1998; $155: 1733-9$.

30. Paris J. Borderline or bipolar? Distinguishing borderline personality disorder from bipolar spectrum disorders. Harv Rev Psychiatry 2004;12:140-5.

31. Gunderson JG. Borderline personality disorder: a clinical guide. Washington: American Psychiatric Press; 2003

32. Paris J, Zweig-Frank H. A 27 year follow-up of patients with borderline personality disorder. Compr Psychiatry 2001;42:482-7.

33. Zanarini MC, Frankenburg FR, Hennen J, Silk KR. The longitudinal course of borderline psychopathology: 6-year prospective follow-up of the phenomenology of borderline personality disorder. Am 7 Psychiatry 2003;160:274-83.

34. Gunderson JG, Morey LC, Stout RL, Skodol AE, Shea MT, McGlashan TH, et al. Major depressive disorder and borderline personality disorder revisited: longitudinal interactions. 7 Clin Psychiatry 2004;65:1049-56.

35. Paris J. Personality disorders over time. Washington: American Psychiatric Press; 2003.

36. Soloff PH, Cornelius J, George A, Nathan S, Perel JM, Ulrich RF. Efficacy of phenelzine and haloperidol in borderline personality disorder. Arch Gen Psychiatry 1993;50:377-85.

37. Cowdry RW, Gardner DL. Pharmacotherapy of borderline personality disorder. Alprazolam, carbamazepine, trifluoperazine, and tranylcypromine. Arch Gen Psychiatry 1988;45:111-9.

38. Zanarini MC, Frankenburg FR. Olanzapine treatment of female borderline personality disorder patients: a double-blind, placebo-controlled pilot study. $\mathcal{F}$ Clin Psychiatry 2001;62:849-54.

39. Zanarini MC. Frankenburg FR. Parachini EA. A preliminary, randomized trial of fluoxetine, olanzapine, and the olanzapine-fluoxetine combination in women with borderline personality disorder. 7 Clin Psychiatry 2004;65:903-7.

40. Bogenschutz MP, Nurnberg GH. Olanzapine versus placebo in the treatment of borderline personality disorder. 7 Clin Psychiatry 2004;65:104-9.
41. Salzman C, Wolfson AN, Schatzberg A, Looper J, Henke R, Albanese M, et al. Effect of fluoxetine on anger in symptomatic volunteers with borderline personality disorder. 7 Clin Psychopharmacol 1995;15:23-9.

42. Coccaro EF, Kavoussi RJ. Fluoxetine and impulsive aggressive behavior in personality-disordered subjects. Arch Gen Psychiatry 1997;54:1081-8.

43. Rinne T, van den Brink W, Wouters L, van Dyck R. SSRI treatment of borderline personality disorder: a randomized, placebo-controlled clinical tria for female patients with borderline personality disorder. Am 7 Psychiatry 2002;159:2048-54

44. Hollander E, Swann AC, Coccaro EF, Jiang P, Smith TB. Impact of trait impulsivity and state aggression on divalproex versus placebo response in borderline personality disorder. Am F Psychiatry 2005;162:621-4.

45. Frankenburg FR, Zanarini MC. Divalproex sodium treatment of women with borderline personality disorder and bipolar II disorder: a double-blind placebo-controlled pilot study. 7 Clin Psychiatry 2002;63:442-6

46. Links PS, Steiner M, Boiago I, Irwin D. Lithium therapy for borderline patients: preliminary findings. 7 Personal Disord 1990;4:173-81.

47. Zanarini MC, Frankenburg FR. Omega-3 fatty acid treatment of women with borderline personality disorder: a double-blind, placebo-controlled pilot study. Am 7 Psychiatry 2003;160:167-9.

48. Shea MT, Pilkonis PA, Beckham E, Collins JF, Elikin E, Sotsky SM, et al Personality disorders and treatment outcome in the NIMH Treatment of Depression Collaborative Research Program. Am 7 Psychiatry 1990;147:711-8.

49. Soloff P. Psychopharmacological treatment of borderline personality disorder. Psychiatr Clin North Am 2000;23:169-92.

50. Linehan MM, Armstrong HE, Suarez A, Allmon D, Heard H. Cognitive behavioral treatment of chronically parasuicidal borderline patients. Arch Gen Psychiatry 1991;48:1060-4.

51. Bohus M, Haaf B, Simms T, Limberger MF, Schmahl C, Unckel C, et al. Effectiveness of inpatient dialectical behavioral therapy for borderline personality disorder: a controlled trial. Behav Res Ther 2004:42:487-99.

52. Simpson EB, Yen S, Costello E, Rosen K, Begin A, Pistorello J, et al. Combined dialectical behavior therapy and fluoxetine in the treatment of borderline personality disorder. 7 Clin Psychiatry 2004;65:379-85.

53. Verheul R, Van Den Bosch LM, Koeter MW, De Ridder MA, Stijnen T, Van Den Brink W. Dialectical behaviour therapy for women with borderline personality disorder: 12-month, randomised clinical trial in The Netherlands. $B r$ 7 Psychiatry 2003;182:135-40.

54. Bateman A, Fonagy P. Effectiveness of partial hospitalization in the treatmen of borderline personality disorder: a randomized controlled trial. Am f Psychiatry 1999;156:1563-9.

55. Paris J. Chronic suicidality in borderline personality disorder. Psychiatr Serv $2002 ; 53: 738-42$

56. Brown MZ, Comtois KA, Linehan MM. Reasons for suicide attempts and nonsuicidal self-injury in women with borderline personality disorder. $7 \mathrm{Ab}$ norm Psychol 2002;111:198-202.

Correspondence to: Dr. Joel Paris, Department of Psychiatry, McGill University, 1033 Pine Ave. W, Montréal QC H3A 1A1; fax 514 398-4370; joel.paris@mcgill.ca

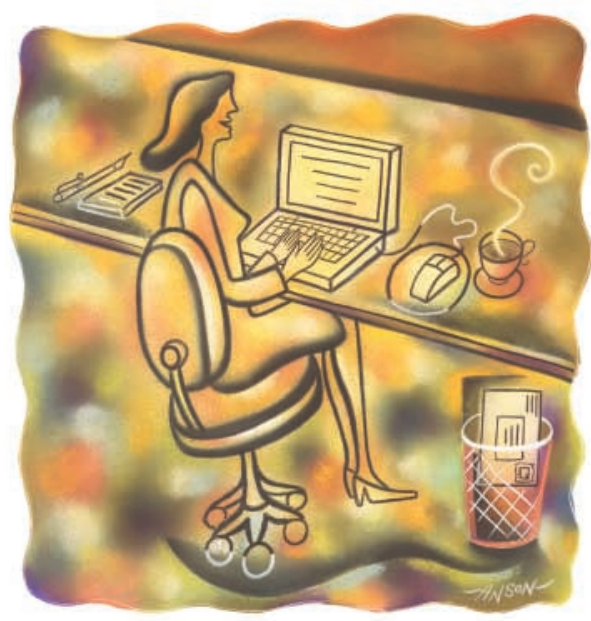

\section{Online manuscript submissions and peer review}

NOW AVAILABLE AT CMAJ http://mc.manuscriptcentral.com/cmaj 